\title{
La circuncisión previene el contagio del virus de la inmunodeficiencia humana
}

\author{
Circumcision prevents human immunodeficiency infection
}

\section{Objetivo}

Investigar el efecto de la circuncisión en la incidencia de infección por el virus de la inmunodeficiencia humana $(\mathrm{VIH})$ en hombres.

\section{Diseño}

Estudio aleatorizado y controlado.

\section{Lugar}

Centros de estudios de comunidades rurales de Rakai, Uganda.

\section{Pacientes}

Hombres VIH negativos de 15 a 49 años de edad, sin contraindicaciones para ser sometidos a cirugía, sin malformaciones genitales (ej. hipospadia) y sin comorbidades peneanas con indicación quirúrgica (ej. fimosis). Fueron asignados en forma aleatoria a alguno de los dos grupos: 1) intervención (circuncisión inmediata); 2) control (circuncisión a los 24 meses).

\section{Intervención}

Se enrolaron 4996 pacientes, 2474 fueron asignados al grupo intervención y 2552 al grupo control.

\section{Medición de Resultados Principales}

Se midió la densidad de incidencia* de VIH cada 100 personas/año. Se hizo un ajuste por edad, estado marital, educación, conductas sexuales de riesgo y síntomas de enfer-

\section{Comentario}

El presente estudio demuestra que la circuncisión disminuye en más de un $50 \%$ la incidencia de $\mathrm{VIH}$ en hombres de poblaciones rurales de Uganda. La eficacia de la circuncisión parece ser lineal y aumentar con el tiempo (25\% al año y $50 \%$ a los dos años) mientras que la aceptabilidad a esta práctica fue importante, ya que el $80 \%$ de los integrantes del grupo control accedió a ser circuncidado una vez finalizado el estudio y por otro lado, no hubo evidencia de que los hombres del grupo intervención adoptaran conductas de mayor riego sexual que los del grupo control. Vale aclarar que tanto este, como otro estudio aleatorizado fueron interrumpidos antes de tiempo luego de que análisis intermedios demostraran una significativa reducción de la incidencia de VIH en la población circuncidada. Sin embargo, hay que tener precaución en la interpretación de estos reportes ya que los estudios interrumpidos antes de tiempo pueden sobreestimar la eficacia de la intervención que está siendo evaluada. Reforzando sus conclusiones admitimos que estos hallazgos son comparables a otros obtenidos en estudios observacionales (estudios ecológicos, metanálisis ${ }^{1}$ de estudios de corte transversal y prospectivos) y estudios aleatorizados realizados en Africa ${ }^{2,3}$, lo que otorga una importante consistencia a sus conclusiones. Gray y col. estimaron un que sería necesario realizar 67 circuncisiones para prevenir un infección por HIV durante los dos años posteriores a la operación. Esta estimación no incluye una posible reduc- medades de transmisión sexual. El análisis se realizó por intención de tratamiento.

\section{Resultados Principales}

El estudio fue terminado precozmente con el $73 \%$ de los participantes seguidos durante 24 meses de comenzado debido a las diferencias surgidas de un análisis preliminar*. Los resultados principales se describen en la tabla 1.

Tabla 1: densidad de incidencia de infección por VIH en el grupo circuncidado inmediatamente y en el circuncidado en forma diferida a los 24 meses.

\begin{tabular}{c|c|c|c}
\hline $\begin{array}{c}\text { Densidad de incidencia (cada } 100 \text { personas/año) } \\
\text { según el momento de la circuncisión }\end{array}$ & RR (IC95\%) & NNT \\
\hline Inmediata & Diferida a los 24 meses & & \\
\hline 0,66 & 1,33 & $0,49(0,29$ a 0,81$)$ & 67 \\
\hline
\end{tabular}

NNT: número necesario a tratar.

\section{Conclusiones}

En una población rural de Uganda, la circuncisión en hombres disminuyó significativamente en un $50 \%$ el riesgo de adquirir $\mathrm{VIH}$.

Palabras claves: circuncisión, ensayo aleatorizado, virus de la inmunodeficiencia adquirida Key words: circumcision, randomized trial, human immunodeficiency virus.

Fuente de financiamiento: Prevention Sciences Research Committee of the Division of AIDS, National Institute of Allergy and Infectious diseases y US National Institute of Health. ción secundaria en el contagio a mujeres y con ello, una menor diseminación del VIH. Es muy importante tener presente que el número de circuncisiones requeridas (NNT) para evitar una infección por $\mathrm{VIH}$, depende de su incidencia poblacional. Por ejemplo, la incidencia de VIH en Argentina ${ }^{4}$ (42 nuevos casos por cada millón de habitantes estimados durante 2004) es mucho menor que la de del estudio que comentamos, por lo que el impacto de la circuncisión sería menos importante en nuestra población.

\section{Conclusiones de la comentadora}

Hasta el momento y solamente superado por la abstinencia sexual, el preservativo es el método anticonceptivo que, además de ser inocuo, mejor protege contra la infección por VIH. El problema es la baja adherencia de la población al mismo, condicionada por factores culturales, históricos y económicos ${ }^{5}$. La circuncisión surge como otra medida alternativa, menos efectiva que el preservativo, pero definitiva y con un nada despreciable $4 \%$ de efectos adversos moderados a severos secundarios a la cirugía. Antes de ser implementada como política sanitaria -que tal vez podría llegar a considerarse como medida sanitaria en neonatos o jóvenes- debería evaluarse la costo-efectividad de esta práctica y su aceptación local ya que la cirugía es una intervención inusual como medida de prevención primaria.

\section{Mariela Weisbrot [ Servicio de Medicina Familiar y Comunitaria. Hospital Italiano de Buenos Aires. mariela.weisbrot@hospitalitaliano.org.ar ]} Recibido el 15/06/07 y aceptado el 15/01/08

Weisbrot M. La circuncisión previene el contagio del virus de la inmunodeficiencia humana. Evid. actual. práct. ambul; 11(1):8, Ene-Feb.2008 Comentado de Gray R, Kigozi G, Serwadda D y col. Male circumcision for HIV prevention in men in Rakai, Uganda: a randomised trial. Lancet. 2007 feb 24;369:657-666. PMID: 17321311.

\section{Referencia}

1. Weiss $\mathrm{H}$, et al circumcision and risk of HIV infection in sub-Saharan Africa: a systematic review and meta-analysis. AIDS 2000; 14: 2361-70.

2. Auvert $B$, et al. Randomized, controlled intervention trial of male circumcision for reduction of HIV infection risk: the ANRS 1265 Trial. PLoS Med 2005; 2: e298.

3. Bailey R, et al. Male circumcision for HIV prevention in young men in Kisumu, Kenya: a randomized controlled trial. Lancet 2007; 369: 643-56.

4. Ministerio de Salud y Ambiente de la Nación. Boletín sobre VIH/Sida en la Argentina. Año X, Número 24, Diciembre 2005. Disponible en URL: http://www.msal.gov.ar/htm/site/sida/site/pdf/BoletinSIDAN24X.pdf (último acceso 15/01/08).

5. Basualdo N, Giraudo N, Discacciati V, Capellato N y López M. ¿Por qué cuesta usar el condón?: opiniones, creencias y conocimientos sobre el uso del preservativo en adultos de un suburbio de Buenos Aires. Archivos de Medicina Familiar y General Volumen 4 Número 2 - 2007 Disponible en URL: http://www.famfyg.org.ar/revista/revista_famfyg/volumen4_n2/05uso_condon.pdf (último acceso 15/01/08). 